\title{
Réplicas, dúplicas y un porvenir para el transhumanismo
}

\author{
doi: $10.52749 /$ fh.v2i2.5
}

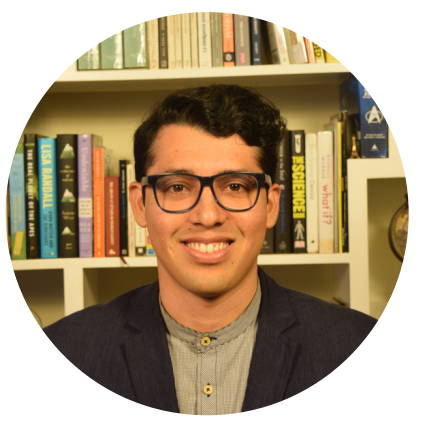

\section{FABRIZIO LÓPEZ DE POMAR ID https://orcid.org/0000-0002-9972-8987}

Licenciado en psicología por la Universidad de Lima. Miembro e investigador de la Sociedad Secular Humanista del Perú (SSH) y del Instituto de Extrapolítica y Transhumanismo (IET). Miembro del Consejo Editorial del Fondo Editorial de la Sociedad Secular Humanista del Perú.

fabrizio.lopez.depomar@gmail.com (0) @beingthebridge

Resumen. Se ha indicado que el transhumanismo es el vehículo filosófico que permitirá el paso de una humanidad a una post-humanidad y ello genera entusiasmo y serias preocupaciones. La finalidad del presente artículo es exponer un breve repaso crítico del proyecto transhumanista para luego señalar un camino que pueda evidenciar al transhumanismo en su aspecto más benévolo, como difícilmente es visto. Para ello, se atiende a las principales críticas con el propósito de justificar la importancia de utilizar las tecnologías de la Cuarta Revolución Industrial en aras del mejoramiento moral, el cual es un proyecto que se exhorta a ser priorizado por el movimiento transhumanista.

Palabras clave: transhumanismo, posthumanismo, mejoramiento moral, homo excelsior.

\section{Introducción}

En este artículo buscaré divulgar y aclarar el "espíritu" transhumanista. Para ello, definiré al transhumanismo y describiré su propósito. Luego, resumiré y responderé alguna de las principales críticas hacia este movimiento. Finalmente, señalaré un camino que considero debe ser seguido por el transhumanismo para demostrarse así mismo que su proyecto busca el bienestar que predica y, de esa manera, resolver las preocupaciones ante los disidentes y profanos en el tema.

\section{¿Qué es el transhumanismo?}

De acuerdo a la asociación mundial Humanity Plus, el transhumanismo es el movimiento intelectual y cultural que afirma la posibilidad y búsqueda de mejorar la condición humana aplicando la razón, la ciencia y sus tecnologías disponibles. El transhumanismo, al igual que el movimiento humanista, desea mejorar nuestras condiciones de vida, pero no solo mediante la educación y los cambios culturales, sino que agrega el uso de la tecnología para superar nuestros límites biológicos (Asociación Mundial de Transhumanismo, s.f.; Tirosh, 2012).

Se puede decir que el transhumanismo es el re- conocimiento explícito, claro y frontal de nuestra histórica tendencia a mejorarnos haciendo uso de las herramientas de cada época. Esto se observa desde tiempos en donde hemos querido cazar de manera más eficiente, mejorar nuestros cultivos, ganar tiempo con mejores medios de transporte, modificar nuestra dieta, capacitarnos mediante talleres o libros, usar prótesis para el cuerpo, mejorar nuestra memoria con una nube de datos, inocularnos una vacuna para mejorar nuestro sistema inmunológico, etc. Es decir, desear un mejor estado físico o psicológico es algo connatural al ser humano. Por lo tanto, la propuesta transhumanista no es novedosa por su esencia, sino por 1) darle un espacio académico a esa tendencia humana, en combinación con las revolucionarias tecnologías actuales y venideras, y 2) tomar así una posición frente a la evolución de la vida humana.

\section{¿Qué se le critica al transhumanismo?}

Réplica \#1: El transhumanismo parece tener problemas para aceptar la naturaleza humana. Como su literatura lo indica, busca expandir los límites biológicos, extender la esperanza de vida hasta llegar a una superlongevidad. Después de todo y, según los transhumanistas, el envejecimien- 
to es un problema técnico. Es válido señalar que el transhumanista tiene algún tipo de rechazo hacia el homo sapiens y que, por eso, el transhumanismo funge como vehículo filosófico hacia un posthumano: esa especie que sería prácticamente irreconocible como humano por sus capacidades e incluso apariencia (e.g. homo excelsior). Por todo lo expuesto, parece que el transhumanista carece de la sabiduría necesaria para aceptar su constitución humana (incluida la mortalidad) y por ello se revela contra la naturaleza.

Dúplica: Los "problemas" que tiene el transhumanista en aceptar los límites biológicos humanos son los mismos que siente cualquier persona cuando se enfrenta a una enfermedad degenerativa o cualquier otra circunstancia de la vida que nos recuerda dichos límites biológicos. Concuerdo con la importancia de cultivar una sabiduría que nos lleve a aceptar nuestro límites y mortalidad, hablemos o no de transhumanismo. Sin embargo, parece forzado identificar al transhumanismo como un movimiento que rechaza al homo sapiens. Si eso fuera así, entonces todo deseo por mejorar algo, incluso la educación o salud de los seres queridos, es el rechazo también a ellos mismos. Uno puede valorar mesuradamente la condición humana y al mismo tiempo apoyar el transhumanismo sin renunciar a la ética o al cultivo de la sabiduría para una mejor administración del poder tecnológico. Esa es la propuesta que enfatizaré más adelante.

Réplica \#2. El transhumanismo, usando la banbandera del mejoramiento humano, reivindica la eugenesia e incrementa las desigualdades en las sociedades, agregando ahora una brecha biológica. Parece tentador afirmar que el transhumanismo no se da cuenta de las enormes desigualdades que existen en el mundo, y a pesar de eso, propone crear un nuevo linaje de personas mejoradas biológicamente. Observemos la situación actual de la pandemia y las vacunas. Solo los que tienen los recursos económicos suficientes han podido mejorar su sistema inmunológico antes que la mayoría. Lo mismo pasará cuando se pueda crear bebés a la carta y modificar su genética hasta donde la tecnología o el dinero lo permitan. Con la excusa de mejorar la especie, reactivan ese deseo de discriminación o purga. La historia ya nos ha mostrado hacia dónde nos puede llevar esa actitud. Si le sumamos la militarización de los posthumanos, el escenario oscurece aún más.

Dúplica: Es posible resumir esa válida preocupación trayendo a colación un dicho popular cuando se menciona la relación del humano con el poder tecnológico: "somos un mono con metralleta". Esa misma preocupación es reunida por un transhumanismo genuinamente interesado en utilizar las tecnologías para hacer "a ese mono" más reflexivo, empático y apto para convivir sabiamente. La época actual hará inevitable que "el mono cambie la metralleta por un lanzacohetes", por lo tanto, el transhumanismo se presenta como un campo académico con efectos prácticos que busca tomar con responsabilidad el control de nuestra propia evolución para que la brecha entre poder tecnológico y sabiduría se vaya acortando con urgencia (López De Pomar, 2020). Considero que por ese camino se podrían resolverán dichos temores.

Réplica \#3. El transhumanismo parece tener una agenda política cuya revolución cultural se viene llevando a cabo hace tiempo; algunos grandes ejemplos son el cine, la literatura de ciencia ficción y los videojuegos. Este movimiento cultural esconde una ideología que busca reducir al ser humano a un objeto, a un artefacto, fusionando lo biológico con lo digital, y elevando el culto a la tecnología al nivel de una nueva religión sin dioses. El transhumanismo, como ideología, tiene la agenda de redefinir nuestra esencia humana, haciendo que nos veamos como artefactos imperfectos que deben arreglarse 0 desecharse. Nuevamente se evidencia que observan al ser humano con desdén.

Dúplica: Esa convergencia de temáticas en el arte puede ser evidencia del imaginario popular inmerso en una época donde las tecnologías permiten soñar con esos escenarios, exista o no la propuesta transhumanista. Por otro lado, presentar al transhumanismo como el responsable de dibujar al ser humano como un artefacto y que eso sea visto como terrible, me parece desmesurado y deshonesto, pues no es el responsable de ello. Una comprensión básica del ser humano nos permite afirmar que funcionamos como máquinas, pero esa mirada mecanicista no le resta valor al ser humano, sino más bien intercambia ese romanticismo adolescente hacia la persona por uno más mesurado que admira y respeta la constitución humana, mientras busca intervenir sobre ella para preservarla, y como insistiré, apuntando a mejoras morales que garanticen una mejor convivencia ecológica.

\section{¿Qué debe hacer el transhumanismo?}

Luego de haber compartido brevemente algunas de las principales críticas al transhumanismo (Bauer, 2010; Benedikter et al., 2010; Vaccari et al., 2020), así 
como algunas respuestas que han sido lo más concisas posibles, daré forma a la sugerencia que encuentro como la más importante para el futuro del transhumanismo. Por cuestión de espacio, señalaré la propuesta de manera breve, dejando un mejor desarrollo para textos posteriores. Entre los principales proyectos del transhumanismo se encuentra el incremento de la longevidad, acercándose a una transcendencia digital; grosso modo, el poder descargar la consciencia en una computadora (mind uploading). Así también, otros proyectos apuntan al incremento de las capacidades físicas y una agilidad mental que supere el actual promedio-alto (Bostrom, 2005; Grant, 2019). Como ya mencioné, comparto la desconfianza hacia el uso del transhumanismo como excusa para dividir y agrandar las brechas de desigualdad. Considero que los constantes y crecientes problemas sociales en el mundo exigen innovaciones en la "ingeniería social", si es que el término es bien recibido. Pensemos en lo siguiente: ¿Cuál sería el principal atributo (físico o psicológico) que mejorarías en el ser humano? Si tuvieras esa varita mágica, ¿qué capacidad humana llevarías al máximo nivel posible?

Muchas respuestas pueden ser interesantes y justificadas. Mi apuesta y exhortación principal de este artículo hacia el transhumanismo inicia por preguntarnos: ¿Pensamos en mejorar la sabiduría? ¿el autoconocimiento? ¿el altruismo? ¿la compasión con uno mismo y con los demás? Desde mi modo de ver las cosas, si hay algo de urgencia por mejorar, es todo el conjunto de capacidades que nos permitirán ser más sabios, reflexivos, compasivos; en suma, mejorar la moral.

El estado de los problemas mundiales, así como los riesgos existenciales (Ord, 2020), fundamentan la urgencia por el cultivo de esos atributos. Persson y
Savulescu (2008) señalan que el mejoramiento cognitivo traerá no solo beneficios indudables, sino también el incremento del riesgo autodestructivo y, por lo tanto, defienden la tesis de una urgente mejora moral que acompañe ese mejoramiento cognitivo. Es por ello que considero que la empresa transhumanista haría bien en demostrarse a sí misma y a sus críticos, que su definición y propósito es un genuino y autocrítico compromiso con el futuro de la especie humana. En otras palabras y de manera más frontal: el transhumanismo debería priorizar el mejoramiento de la moral antes que cualquier otro proyecto. Si no mejoramos con urgencia nuestras capacidades para mantener el equilibrio social y medioambiental, no habrá mejoras que valgan ni un futuro tan prometedor como queremos creer.

\section{Conclusión}

El transhumanismo es el reconocimiento y aceptación de nuestra tendencia histórica a mejorarnos con las tecnologías disponibles de cada época. Este reconocimiento fija a su vez una posición comprometida frente a la evolución de la vida humana. La exposición de críticas y respuestas buscó dimensionar las preocupaciones válidas. Finalmente, se presentó una reflexión que exhorta a los proyectos transhumanistas a priorizar uno sobre los demás: el mejoramiento de la moral. En suma, este artículo buscó aclarar el concepto del transhumanismo y reconsiderar su propósito y valor. De esa manera, el transhumanismo aparece como una propuesta responsable que le da un espacio académico a la reflexión y aplicación de las nuevas tecnologías de esta Cuarta Revolución Industrial en aras de una mejor humanidad.

Bostrom, N. (2005). Transhumanist Values. Review of Contemporary Philosophy, 4(1-2), 87-101.

Grant, A. (2019). Will human potencial carry us beyond human? A humanistic inquiry into transhumanism. Journal of Humanistic Psychology, 1(1), 1-15. https://doi.org/10.1177/0022167819832385

López De Pomar, F. (2020). Tecnología y autoconocimiento: la otra brecha que debemos reducir. Futuro Hoy, 1(1). https://doi.org/10.52749/fh.v1i1.3

Ord, T. (2020). The precipice. Existencial risk and the future of humanity. Hachette Books. 
Persson, I., \& Savulescu, J. (2008). The perils of cognitive enhancement and the urgent imperative to enhance the moral character of humanity. Journal of applied philosophy, 25(3), 162177.
Tirosh-Samuelson, H. (2012). Transhumanism as a secularist faith. Zygon, 47(4), 710-734. https://doi.org/10.1111/j.14679744.2012.01288.x

Vaccari, A., \& Fisher, J. (2020). El transhumanismo como opiáceo tecnocientífico. Pensando-Revista de Filosofia, 11(23), 2-14. https://doi.org/10.26694/pensando.v11i23.11037

\section{Cómo citar este artículo:}

López de Pomar, F. (2021). Réplicas, dúplicas y un porvenir para el transhumanismo. Futuro Hoy, 2(2), 31-34. https://doi.org/10.52749/fh.v2i2.5

Esta obra está bajo licencia internacional

Creative Commons 4.0 Reconocimiento 4.0. 